\title{
Relationship Between Student QoL With Irritable Bowel Syndrome and Related Factors at Ahvaz Jundishapur University of Medical Sciences
}

\author{
Masoumeh Asadi ${ }^{1}$; Mohamad Ghasemi Deh Cheshmeh ${ }^{2}$; Moosa Mahmoodi ${ }^{3}$; Kourosh \\ Zarea ${ }^{4}$; Ali Ghomeishi ${ }^{5}$; Sara Adarvishi ${ }^{1, *}$ \\ ${ }_{2}$ Student Research Committee, Nursing and Midwifery School, Ahvaz Jundishapur University of Medical Sciences, Ahvaz, IR Iran \\ ${ }_{3}^{2}$ Department of Immunology, Ahvaz Jundishapur University of Medical Sciences, Ahvaz, IR Iran \\ ${ }^{3}$ Department of Statistics, Shahid Chamran University, Ahvaz, IR Iran \\ ${ }_{5}^{4}$ Chronic Disease Care Research Center, Ahvaz Jundishapur University of Medical Sciences, Ahvaz, IR Iran \\ ${ }^{5}$ Department of Anesthesiology, Ahvaz Jundishapur University of Medical Sciences, Ahvaz, IR Iran \\ ${ }^{*}$ Corresponding author: Sara Adarvishi, Department of Nursing and Midwifery, Ahvaz Jundishapur University of Medical Sciences, Ahvaz, IR Iran. Tel: +98-9166221628, E-mail: sara. \\ adarvishi@yahoo.com \\ Received: August 15, 2014; Revised: October 5, 2014; Accepted: October 28, 2014
}

\begin{abstract}
Background: Irritable bowel syndrome (IBS) is one of the most common functional disorders of the lower gastrointestinal tract characterized by abdominal pain and changes in bowel habits. This disorder changes the QoL (QoL) for patients.

Objectives: This study examines the relationship between QoL for nursing students with other associated factors.

Patients and Methods: These descriptive-analytic studies indicate a census for 57 senior nursing students of the School of NursingMidwifery, Ahvaz in 2013-2014. The data from the demographic questionnaire and QoL questionnaire (QOL-34) was collected. Data using ANOVA and t-tests with significance level of $\mathrm{P}<0.05$ were analyzed.

Results: Out of 57 nursing students, there were 45 healthy subjects and 12 subjects with IBS. Mean scores for patient QoL (117.92 \pm 5.87$)$ and normal patient QoL was (49.38 \pm 5.01$)$, which indicates a significantly lower QoL. The T-test and ANOVA showed that among age, gender, marital status, living location, and QoL, there were no significant relationships $(\mathrm{P}>0.05)$. While for QoL and academic Grade Point Average $(\mathrm{P}=0.048)$, ethnicity $(\mathrm{P}=0.006)$, disease duration $(\mathrm{P}=0.049)$, and disease severity $(\mathrm{P}=0.030)$ were significantly related .

Conclusions: It seems important to pay attention to health problems and to apply interventions that will influence QoL. Lifestyle changes and staying away from activities that are associated with tension stress can help to eliminate the symptoms and disease severity and improve the QoL for student.
\end{abstract}

Keywords:Irritable Bowel Syndrome; QoL; Students

\section{Background}

IBS is a chronic functional gastrointestinal disorder characterized by changes in bowel habits (diarrhea, constipation) and abdominal pain and bloating in the absence of chemical and pathological disorders, which fluctuates irregularly but is not completely eliminated $(1,2)$. The syndrome has several different names such as spastic colon, irritable colon, or nervous colon (3). It affects all races and ages in both genders (4), but most studies indicate it has a higher prevalence in women $(5,6)$. Also, the prevalence of IBS varies worldwide so that the rate varies from 9-22\% in the United States and European countries (7) to its lowest rates of $4.2 \%$ and $4.4 \%$ in Northern India and Thailand, respectively (8). Based on population studies conducted in Iran, IBS prevalence has been reported between 3.5-5.8\% (9). The severity of symptoms of IBS varies from mild discomfort to a severe debilitating illness. The disease can be associated in some cases with fecal urgency and incontinence, extra intestinal symptoms such as drowsiness, urinary problems, and sexual symptoms. Sometimes the symptoms are so disturbing that even some patients have attempted suicide because there was no prospect of recovery (10). Symptoms of IBS may overlap with those of other conditions, therefore, many patients, due to misdiagnosis; undergo surgeries such as appendectomy, cholecystectomy, or hysterectomy, among others. (11). In North America, the disease is the second leading cause of absenteeism after the common cold and patients suffering from the disease have had to quit work three times more than others (12). Although the exact and main cause of IBS is unknown, many studies have shown that several factors such as genetics, environment, mental state, brain abnormal central processing, hormonal changes, dietary habits, and activation of the immune system are involved (13). Stress, anxiety, and depression are common in patients with IBS and have a significant relationship with the onset and severity of IBS symptoms (14).

The prevalence of IBS in Korean medical students is 29.2 $\%(15)$ while the reported level among Iranian medical and non-medical students varies across cities ranging from 4.2-18.4\% (11). Several studies have shown that nurses

Copyright (c) 2015, Ahvaz Jundishapur University of Medical Sciences. This is an open-access article distributed under the terms of the Creative Commons Attribution-NonCommercial 4.0 International License (http://creativecommons.org/licenses/by-nc/4.0/) which permits copy and redistribute the material just in noncommercial usages, provided the original work is properly cited. 
participating in shift work will have a higher prevalence of IBS, which is associated with either sleep disorder or a disruption of biological rhythms (16-18). Nowadays, students including nurse-midwifery students face many stressful situations (events) in terms of their educational experience in which they find themselves in a high-stress and complex setting with psychological pressure from the environment (hospital, patient problems), course work and training, economic problems, family problems and lack of carrier opportunities (19). They also experience higher stress levels than others do, which indicates that stress and anxiety play a major role in $\operatorname{IBS}(20,21)$.

IBS, in addition to the high health care costs, decreases efficiency and reduces the QoL (QoL) for individuals and depending on symptom severity; they experience a certain degree of impairment of QoL fora significant number of patients. The disease can have devastating effects on inter personal relationships as well as on occupational functioning and makes them abstain from sex and even refrain from attending gatherings and traveling out of a fear of causing symptoms. QoL for these patients is reportedly lower than the general population and healthy subjects $(22,23)$. Sun Cho (2011) showed that the average QoL in patient score with IBS was 78.9 and that they had a lower score in all aspects (24).

Tamannaifar et al. also showed that the average QoL score in patients with IBS (101.21) is higher when compared with healthy subjects (47.31) $(\mathrm{P}<0.001)$. Therefore, a higher score indicates a lower QoL. The patient average scores for components of QoL including dysphonia ( $\mathrm{P} \leq 0.002)$, social reaction $(P \leq 0.002)$, intervention $(P \leq 0.019)$, positive body image $(P \leq 0.003)$, health anxiety $(P \leq 0.0001)$, social communication ( $\mathrm{P} \leq 0.007)$, and sexual concern $(P \leq 0.002)$ are significantly lower. There was no significant difference with respect to food avoidance (25). In one study, the effects of this disease on QoL are considered to be the same as that of diabetes, congestive heart failure, kidney failure, and liver cirrhosis (26). The present study evaluates the QoL of patients with IBS and healthy control subjects because of the high prevalence of the disease and its impact on job performance, education, and family.

\section{Objectives}

This research was designed to investigate the relationship between students with IBS and their QoL and some related factors at Ahvaz Jundishapur University of Medical Sciences.

\section{Patients and Methods}

In this cross-sectional (descriptive-analytic) study, the students with IBS QoL at Ahvaz Jundishapur University of Medical Sciences is discussed. Undergraduate students in the School of Nursing and Midwifery in the academic year 2013-2014 were studied using the census method. After obtaining written consent, 57 students completed the study data.After arranging with School of Nursing and Midwifery registrar office and with regard to student class schedules, the classes were visited for a week when students were not taking exams or in their preparation period. The first few minutes of each class were devoted to explain the purpose of the research. They were also informed that they should give accurate responses and that their results will remain confidential. Then the questionnaires were encoded. It is noteworthy that the students who did not attend classes completed the questionnaires in their dormitories as per the above-mentioned procedure. To collect information about the symptoms of students with IBS, a checklist was prepared (made) by the researcher based on the Rome III diagnostic criteria for IBS was used, which then was filled out by the students when completing the questionnaires.

The Rome III diagnostic criteria is defined as follows: abdominal pain or discomfort, clear-cut change in bowel habits, for at least six months, with symptoms being present for at least 3 days (per month) in the last 3 months associated with two or more of the following: pain improvement with defecation, pain onset associated with a change in frequency of stool, pain onset associated with a change in form or appearance of stool (27). Research instruments included demographic data containing demographic characteristics such as age, gender, marital status, residence, academic GPA, ethnicity, symptoms, duration of illness, and severity of illness. To assess QoL, the IBS-QOL-34 questionnaire was used. The IBS-QOL-34 Questionnaire for patients with IBS in was made by Patrick and Dross in 1998. It is the best tool available to assess QoL in these patients. The scale consists of 34 questions based on a five-point Likert scale (never, rarely, usually, often, or always) answered by the patient.

The maximum score is 170 and the minimum score is 34.Higher scores on the IBS-QOL indicate poorer QoL. The questionnaire consists of eight subscales and assesses: dysphoria (questions 1, 3, 6, 7, 9, 10, 13, 16, and 30), social reaction (questions 2,14, 17, and 34), health concern (questions 4, 15, and 32), body image (questions 5, 21, 23, and 26), interpersonal relations (questions 8, 25, and 33), food avoidance (questions 11, 24, and 28 ), sexual function (questions 12 and 20), and interference with activity (questions 18, 19, 22, 27, 29, and 31).

This test is highly reliable and has been confirmed by several studies. The reliability of this test in America, Europe, and Asia is reportedly 0.95, 0.96, and 0.96, respectively. The overall reliability of the Persian version of the test is 0.92 (28). Information was obtained by SPSS (ver 19) and analyzed by the one-way ANOVA and independent t-test with a level of significance of $P \leq 0.05$. The initial plan of the study was approved by the Ethics Committee of Ahvaz Jundishapur University of Medical Sciences with code No. ajums (REC.1393.16).

\section{Results}

A total of 57 nursing students participated in this study with 45 healthy subjects (78.9\%) and 12 subjects with IBS (21.1\%); 46 were women (80.7\%) and 11 males (19.3\%); 10 
Asadi M et al.

(83.3\%) out of 12 subjects with IBS were women and the rest were men; and 43 patients (75.4\%) of the participants were single and 14 (34.6\%) were married. Of the 12 patients with IBS, 10 patients (83.3\%) were single and 2 patients (16.7\%) were married. Ethnic breakdown of the participants was as follows: 22 participants were Persian (38.6\%), 20 were Lur (35.1\%), 13 subjects were Arab (22.8\%), and 2 (3.5\%) were Kurd. Of subjects with IBS 5 (41.7\%) were Persian, 3 patients (25\%) were Arab, 3 patients (25\%) were Lurs, and 1 patient was Kurd. Thirty-seven (64.9\%) participants were living in a dormitory and 20 subjects (35.1\%) were non-dormitory students. Eight (66.7\%) subjects were dormitory students and the rest were non-dormitory. The findings showed that there was not a significant relationship among the variables such as age, gender, marital status, place of residence, symptoms (diarrhea, constipation, diarrhea, and constipation), and QoL of students with IBS (P > 0.05), whereas there was a significant relationship between the QoL and GPA $(P=0.048)$, ethnicity $(P=0.006)$, disease duration $(\mathrm{P}=0.049)$, and disease severity $(\mathrm{P}=0.030)$, (Table 1$)$.

One-way ANOVA test showed a statistically significant relationship between two aspects of body image and daily activity as well as with duration of disease $(P<0.05)$ (Table 2). In addition, there was not any significant correlation between any aspect of life quality and disease severity (Table 3 ). The results show that the mean scores of QoL variables in patients are (117.92 \pm 5.87$)$ and in ordinary people are $(49.38 \pm 5.01)$. A high score indicates a low level of QoL for patients with IBS $(\mathrm{P}=0.001)$ (Table 4).

Table 1. Comparison of QoL Scores in Patients According to the Characteristics Using the t-test and Fisher ${ }^{a}$

\begin{tabular}{|c|c|c|c|}
\hline Variables & \multicolumn{2}{|c|}{ QoL Scores } & PValue \\
\hline$\leq 23$ & $3(25.0)$ & $117.00 \pm 6.93$ & \\
\hline$>23$ & $9(75.0)$ & $118.22 \pm 5.91$ & \\
\hline Gender & & & 0.521 \\
\hline Male & $2(16.7)$ & $120.50 \pm 7.78$ & \\
\hline Female & $10(83.3)$ & $117.40 \pm 5.80$ & \\
\hline $\begin{array}{l}\text { Marital } \\
\text { status }\end{array}$ & & & 0.607 \\
\hline Single & $10(83.3)$ & $117.50 \pm 6.38$ & \\
\hline Married & $2(16.7)$ & $120.00 \pm 1.41$ & \\
\hline Location & & & 0.721 \\
\hline Dormitory & $8(66.7)$ & $118.38 \pm 5.40$ & \\
\hline $\begin{array}{l}\text { No dormi- } \\
\text { tory }\end{array}$ & $4(33.3)$ & $117.00 \pm 5.23$ & \\
\hline $\begin{array}{l}\text { Grade Point } \\
\text { Average }\end{array}$ & & & 0.048 \\
\hline $12-13.99$ & $2(16.7)$ & $121.00 \pm 0$ & \\
\hline 14-15.99 & $9(75.0)$ & $118.56 \pm 5.18$ & \\
\hline $16>$ & $1(8.3)$ & $106.00 \pm 0$ & \\
\hline Ethnicity & & & 0.006 \\
\hline Fars & $5(41.7)$ & $121.00 \pm 2.92$ & \\
\hline Arab & $3(25.0)$ & $111.67 \pm 4.93$ & \\
\hline Lor & $3(25.0)$ & $122.00 \pm 1.00$ & \\
\hline Kord & $1(8.3)$ & $109.00 \pm 0$ & \\
\hline
\end{tabular}

Table 2. Comparison of Mean Scores of QoL in Patients With Irritable Bowel Syndrome according to Duration of Disease using the Fisher Test ${ }^{a}$

\begin{tabular}{|c|c|c|c|c|}
\hline \multirow[t]{2}{*}{ Variables } & \multicolumn{3}{|c|}{ Duration of Disease, $y$} & \multirow[t]{2}{*}{ P Value } \\
\hline & $2>$ & $2-4$ & $\mathbf{4}<$ & \\
\hline QoL & $119.11 \pm 4.78$ & $118.50 \pm 6.36$ & $106.00 \pm 0$ & 0.049 \\
\hline $\begin{array}{l}\text { Helpless- } \\
\text { ness and } \\
\text { boredom }\end{array}$ & $34.44 \pm 2.60$ & $34.50 \pm .71$ & $32.00 \pm 0$ & 0.649 \\
\hline $\begin{array}{l}\text { Social } \\
\text { reaction }\end{array}$ & $12.67 \pm 1.23$ & $11.50 \pm 6.36$ & $10.00 \pm 0$ & 0.538 \\
\hline $\begin{array}{l}\text { Health } \\
\text { concerns }\end{array}$ & $11.67 \pm 1.00$ & $13.00 \pm 0$ & $12.00 \pm 0$ & 0.247 \\
\hline Body Image & $12.56 \pm 1.42$ & $13.00 \pm 0$ & $9.00 \pm 0$ & 0.048 \\
\hline $\begin{array}{l}\text { Interper- } \\
\text { sonal com- } \\
\text { munication }\end{array}$ & $10.33 \pm 1.80$ & $9.00 \pm 2.83$ & $12.00 \pm 0$ & 0.468 \\
\hline $\begin{array}{l}\text { Food } \\
\text { avoidance }\end{array}$ & $11.67 \pm 1.41$ & $11.00 \pm 1.41$ & $11.00 \pm 0$ & 0.784 \\
\hline $\begin{array}{l}\text { Sexual } \\
\text { function }\end{array}$ & $4.22 \pm 2.22$ & $2.50 \pm 0.71$ & $2.00 \pm 0$ & 0.433 \\
\hline $\begin{array}{l}\text { Activities of } \\
\text { daily living }\end{array}$ & $21.56 \pm 1.94$ & $24.00 \pm 1.41$ & $18.00 \pm 0$ & 0.049 \\
\hline
\end{tabular}

a Data are presented as Mean \pm SD.

Table 3. Comparison of Mean Scores of QoL in Patients With Irritable Bowel Syndrome According to Severity of Disease using the Fisher Test ${ }^{\text {a }}$

\begin{tabular}{lcccc}
\hline Variables & Mild & Average & Extreme & P Value \\
\hline QoL & $124.50 \pm 2.12$ & $120.50 \pm 1.29$ & $114.00 \pm 5.73$ & 0.030 \\
$\begin{array}{l}\text { Helpless- } \\
\text { ness and } \\
\text { boredom }\end{array}$ & $34.50 \pm 0.71$ & $34.75 \pm 2.22$ & $33.83 \pm 2.93$ & 0.848 \\
\hline $\begin{array}{l}\text { Social } \\
\text { reaction }\end{array}$ & $15.00 \pm 1.41$ & $12.25 \pm 1.50$ & $11.33 \pm 2.50$ & 0.160 \\
$\begin{array}{l}\text { Health } \\
\text { concerns }\end{array}$ & $11.50 \pm 2.12$ & $11.75 \pm 0.957$ & $12.17 \pm 0.753$ & 0.700 \\
\hline $\begin{array}{l}\text { Body Image } \\
14.00 \pm 1.41\end{array}$ & $12.75 \pm 1.50$ & $11.50 \pm 1.38$ & 0.131 \\
\hline $\begin{array}{l}\text { Interper- } \\
\text { sonal com- } \\
\text { munication }\end{array}$ & $12.00 \pm 1.41$ & $10.75 \pm 2.06$ & $9.33 \pm 1.63$ & 0.198 \\
\hline $\begin{array}{l}\text { Food } \\
\text { avoidance }\end{array}$ & $11.00 \pm 1.41$ & $11.75 \pm 1.50$ & $11.50 \pm 1.38$ & 0.834 \\
$\begin{array}{l}\text { Sexual } \\
\text { function }\end{array}$ & $3.00 \pm 0.000$ & $4.25 \pm 2.63$ & $3.67 \pm 2.25$ & 0.813 \\
\hline $\begin{array}{l}\text { Activities of } \\
\text { daily living }\end{array}$ & $23.50 \pm 0.707$ & $22.25 \pm 1.71$ & $20.67 \pm 2.58$ & 0.276 \\
\hline \begin{tabular}{l} 
a Data are presented as Mean $\pm S D$ \\
\hline
\end{tabular} & & & \\
\hline
\end{tabular}


Asadi M et al.

Table 4. Comparison of Mean Scores of QoL according to Disease Status using the t-test ${ }^{a}$

\begin{tabular}{lccc}
\hline Variables & IBS Patient & Healthy & P Value \\
\hline QoL & $117.92 \pm 5.87$ & $49.38 \pm 5.01$ & 0.001 \\
\hline $\begin{array}{l}\text { Helplessness } \\
\text { and boredom }\end{array}$ & $34.25 \pm 2.34$ & $11.85 \pm 1.69$ & 0.001 \\
\hline Social reaction & $12.25 \pm 2.34$ & $5.32 \pm 1.01$ & 0.001 \\
\hline Health concerns & $11.92 \pm 0.996$ & $3.89 \pm 0.716$ & 0.001 \\
\hline Body Image & $12.33 \pm 1.61$ & $6.24 \pm 1.22$ & 0.001 \\
\hline $\begin{array}{l}\text { Interpersonal } \\
\text { communication }\end{array}$ & $10.25 \pm 1.91$ & $4.31 \pm 1.06$ & 0.001 \\
\hline $\begin{array}{l}\text { Food avoidance } \\
\text { Sexual function }\end{array}$ & $11.50 \pm 1.31$ & $7.19 \pm 1.78$ & 0.001 \\
\hline $\begin{array}{l}\text { Activities of } \\
\text { daily living }\end{array}$ & $21.67 \pm 2.27$ & $8.25 \pm 1.39$ & 0.001 \\
\hline
\end{tabular}

$\mathrm{a}$ Data are presented as Mean \pm SD.

\section{Discussion}

The findings of this study show that the QoL scores and all its aspects for the students with IBS are higher compared to healthy subjects, which represents a lower QoL for students with IBS. Indifferent studies, the QoL of these patients is reportedly lower than for healthy subjects and the general population $(22,23)$ Tamannaifar et al. showed that compared to healthy subjects (47.31), the mean QoL scores in patients with IBS is higher in all aspects except for food avoidance (101.21) (25); i.e. the higher the score, the lower QoL among patients with IBS. Sun Cho also showed that compared to healthy controls, the QoL mean score in patients with IBS was 78.9, which reflects a lower score in all aspects (24). Faresjo et al. also indicated that QoL is lower in patients with IBS (29), which is consistent with the present study. Frequency for female IBS patients (83.3\%) is higher than for men (16.7\%). This difference was not statistically significant. This is probably because in the study population, women participated more than men did. Another reason is that women pay more attention to their health (30) and they are more likely than men to consult a physician or use health care services. In examining the relationship among QoL, gender, and marital status, there were not any significant relationships, which was consistent with Kanazawa et al. (31).

The results showed that there was a significant relationship between QoL and GPA. This means that a student with IBS and a low GPA will experience a lower QoL.

Student GPA seems to be associated with stress levels. Students with a lower GPA fear being placed on probation or they may be unable to achieve necessary results due to higher levels of stress. As shown in previous studies, stress management for students with IBS can help them to have a better education, improve their symptoms, and QoL dramatically (32).

Our results show there is not a statistically significant association between QoL and symptoms, nor did Sun Cho (24), Kanazawa (31), and Jamali et al. (33). In Jamali's study, the score of QoL for patients was as follows: patients with diarrhea-predominant symptoms (76.43 \pm 19.13$)$, patients with constipation-predominant symptoms (80.28 \pm 25.57), and patients with symptoms of diarrhea and constipation ( $57.25 \pm 7.71$ ), which was not statistically significant and consistent with the present study. The results of the present study are inconsistent with results obtained by Muscatello et al. (34).

Muscatello et al. (34) has demonstrated that QoL in patients with IBS with constipation and mixed symptoms was lower than for symptoms of diarrhea, the cause of which could be the result of higher levels of prolactin, which in turn is the result of Vagus nerve activity. Anxiety and depression in patients with constipation-predominant symptoms is more commonly reported and is another reason for the lower QoL in these patients. The improvement in symptoms of IBS is associated with an improvement in QoL, which may reduce psychological symptoms such as anxiety and depression (35). As the findings show, a significant relationship was found between QoL and symptom severity. The QoL score in patients with severe symptoms was higher than for patients with mild and moderate symptoms, which indicates the lower QoL of the former.

Many studies have reported that impairments of the QoL in patients with IBS are related to symptom severity $(36,37)$. Similar results have been reported by Sun Cho (24) and by Hasler et al. (38). Therefore, mental breakdown is thought to affect the onset or exacerbation of a gastrointestinal symptoms in patients with IBS (39). Several studies have noted that the greater the severity of the symptom, the greater the contribution to psychological factors (40). The results of this study indicate a significant association between illness duration and QoL. The significant relationship could be due to the adjustment during the duration of illness and those who have been affected with the disease for longer have adjusted well to their illness conditions than for those who have been affected shorter.

It is indicated that the enteric nervous system is extremely sensitive to emotional states and that stress and negative emotions create changes in intestinal motor activity that can cause intestinal symptoms such as the symptoms of IBS (41). In addition, the increased knowledge, passion, and enthusiasm for upgrading generate concern for educated people. This concern causes stress and anxiety, which is an underlying cause of IBS. On the other hand, educated people are typically busy without enough time for the right food. Therefore, with increased consumption of fast-food, they experience more bowel problems and as stress and depression can have a direct relationship with symptom severity, nursing students are exposed to stressful experiences in the learning environment as well as in the clinical environment. As factors influencing health such as the severity and duration of 
the illness affect daily activities, and in general may diminish QoL for students with IBS, it is essential for universities to pay attention to the physical and mental health of students.

The limitations of this study include lack of cooperation in completing the questionnaires, and the information obtained from participants is merely based on their remarks, which may contain errors in the responses. According to the results, this research suggests doing similar research among other medical students with larger samples.

The results indicate that QoL is lower among nurses with IBS. Since personal factors are associated with QoL in patients with IBS, to improve their QoL, it seems important to pay attention to health problems and to apply interventions that will influence QoL.

Lifestyle changes and staying away from activities that are associated with tension stress can help to eliminate the symptoms and disease severity and improve the QoL for nurses, because there is a relationship between stressful events and the onset of disease

\section{Acknowledgements}

This paper was supported by Ahvaz Jundishapur University of Medical Sciences. Hereby, we acknowledge the deputy vice-chancellor for research and technology affairs of Ahvaz Jundishapur University of Medical Sciences as well as all patients who participated in this study.

\section{Authors' Contributions}

Study concept and design: Masoomeh Asadi, Sara Adarvishi. Analysis and interpretation of data: Moosa Mahmoodi, Mohamad Ghaseni Deh Cheshmeh, Sara Adarvishi. Manuscript preparation: Masoumeh Asadi, Sara Adarvishi, Kourosh Zare, Ali Ghomeishi. Collection of data: Masoumeh Asadi, Sara Adarvishi. Critical revision: Sara Adarvishi, Masoumeh Asadi, Kourosh Zare, Mohamad Ghasemi Deh Cheshmeh, and Ali Ghomeishi.

\section{Funding/Support}

Ahvaz Jundishapur University of Medical Sciences, vicechancellor for research and technology.

\section{References}

1. Anbardan SJ, Daryani NE, Fereshtehnejad SM, Taba Taba Vakili S, Keramati MR, Ajdarkosh H. Gender Role in Irritable Bowel Syndrome: A Comparison of Irritable Bowel Syndrome Module (ROME III) Between Male and Female Patients. J Neurogastroenterol Motil. 2012;18(1):70-7.

2. Zargar Y, Davoudi I, Fatahinia M, Masjedizadeh AR. [Comparison of personality traits of irritable bowel syndrome (IBS) paitients and healthy population with control of mental health in Ahvaz]. Sci Med. 2011;10(2):131-9.

3. Moghadaszadeh M, Fatahi E, Bonyadi M, Shirzadeh M. [Effect of food llergenexculsion on symptoms and quality of life in irritable bowel syndrome]. J Gorgan Univ Med Sci. 2012;14(3):87-91.

4. SeyedMirzaee SM, Mahmoodi M, Bakhshi H, Montezeri M. [A Survey on Testosterone Blood Levels in Male Irritable Bowel Syn- drome Patients in Comparison with a Control Group]. Govaresh. 2010;15(2):104-9.

5. Sadrkabir S, Afshar H, Adibi P, Meraasi M, Daghaghzadeh H, Mojtahedzadeh A. Effect of Citalopram and Olanzapine Combinations in the Treatment of Refractory Irritable Bowel Syndrome. Govaresh. 2010;14(4):269-74.

6. Thomas RH, Allmond K. Linaclotide (Linzess) for Irritable Bowel syndrome With Constipation and For Chronic Idiopathic Constipation. PT. 2013;38(3):154-60.

7. Makharia GK, Verma AK, Amarchand R, Goswami A, Singh P, Agnihotri A, et al. Prevalence of irritable bowel syndrome: a community based study from northern India. J Neurogastroenterol Motil. 2011;17(1):82-7.

8. Ghoshal UC, Abraham P, Bhatt C, Choudhuri G, Bhatia SJ, Shenoy KT, et al. Epidemiological and clinical profile of irritable bowel syndrome in India: report of the Indian Society of Gastroenterology Task Force. Indian J Gastroenterol. 2008;27(1):22-8.

9. EbrahimiDaryani N, Shirzad, Taher M. [Irritable Bowel Syndrome: A Review of Diagnosis and Treatmen]. J Med Counc I.R. Iran. 2011;29(1):50-67.

10. Miller V, Hopkins L, Whorwell PJ. Suicidal ideation in patients with irritable bowel syndrome. Clin Gastroenterol Hepatol. 2004;2(12):1064-8.

11. Rezahosseini O, Seyedmirzaee S. M. , Sayadi AR, Sataei Mokhtari S. [Frequency of Irritable Bowel Syndrome among Students of Rafsanjan University of Medical Sciences; 2008-2009].J RafsanjanUniv Med Sci. 2012;11(2):137-44.

12. Modabbernia MJ, Mansour-Ghanaei F, Imani A, Mirsafa-Moghaddam SA, Sedigh-Rahimabadi M, Yousefi-Mashhour M, et al. Anxiety-depressive disorders among irritable bowel syndrome patients in Guilan, Iran. BMC Res Notes. 2012;5:112.

13. Drossman DA. The functional gastrointestinal disorders and the Rome III process. Gastroenterology. 2006;130(5):1377-90.

14. Gholamrezaei A, Minakari M, Nemati K, Daghaghzadeh H, Tavakkoli H, Emami MH. Extra-intestinal Symptoms and their Relationship to Psychological Symptoms in Patients with Irritable Bowel Syndrome. Govaresh. 2010;15(2):88-94.

15. Jung HJ, Park MI, Moon W, Park SJ, Kim HH, Noh EJ, et al. Are Food Constituents Relevant to the Irritable Bowel Syndrome in Young Adults? - A Rome III Based Prevalence Study of the Korean Medical Students. J Neurogastroenterol Motil. 2011;17(3):294-9.

16. Nojkov B, Rubenstein JH, Chey WD, Hoogerwerf WA. The impact of rotating shift work on the prevalence of irritable bowel syndrome in nurses. Am J Gastroenterol. 2010;105(4):842-7.

17. Saberi HR, Moravveji AR. Gastrointestinal complaints in shiftworking and day-working nurses in Iran. J Circadian Rhythms. 2010;8:9.

18. Zhen Lu W, Ann Gwee K, Yu Ho K. Functional bowel disorders in rotating shift nurses may be related to sleep disturbances. Eur J Gastroenterol Hepatol. 2006;18(6):623-7.

19. Areshtanab HN, Ebrahimi H, SahebiHagh MH, Arshadi Bostanabad M. [Mental Health Status and Its Relationship with Academic Achievement in Students of Tabriz Nursing-Midwifery School]. Iran J Med Educ. 2013;13(2):146-52.

20. Naeem SS, Siddiqui EU, Kazi AN, Memon AA, Khan ST, Ahmed B. Prevalence and factors associated with irritable bowel syndrome among medical students of Karachi, Pakistan: a cross-sectional study. BMC Res Notes. 2012;5:255.

21. Shen L, Kong H, Hou X. Prevalence of irritable bowel syndrome and its relationship with psychological stress status in Chinese university students.J Gastroenterol Hepatol. 2009;24(12):1885-90.

22. Brun-Strang C, Dapoigny M, Lafuma A, Wainsten JP, Fagnani F. Irritable bowel syndrome in France: quality of life, medical management, and costs: the Encoli study. Eur J Gastroenterol Hepatol. 2007;19(12):1097-103.

23. Lea R, Whorwell PJ. The role of food intolerance in irritable bowel syndrome. Gastroenterol Clin North Am. 2005;34(2):247-55.

24. Sun Cho H, Park JM, Lim CH, Cho YK, Lee IS, Kim SW, et al. Anxiety, depression and quality of life in patients with irritable bowel syndrome. Gut Liver. 2011;5(1):29-36.

25. Tamannaifar MR, Akhavan-Hejazi ZS. Comparing the mental health and quality of life in patients with irritable bowel syn- 
drome and healthy subjects in Kashan, Iran. Kashan Univ Med Sci. 2013;17(2):195-202.

26. El-Salhy M. Irritable bowel syndrome: diagnosis and pathogenesis. World J Gastroenterol. 2012;18(37):5151-63.

27. Dai N, Cong Y, Yuan H. Prevalence of irritable bowel syndrome among undergraduates in Southeast China. Dig Liver Dis. 2008; 40 (6):418-24.

28. Groll D, Vanner SJ, Depew WT, DaCosta LR, Simon JB, Groll A, et al. The IBS-36: a new quality of life measure for irritable bowel syndrome. Am J Gastroenterol. 2002;97(4):962-71.

29. Faresjo A, Anastasiou F, Lionis C, Johansson S, Wallander MA, Faresjo T. Health-related quality of life of irritable bowel syndrome patients in different cultural settings. Health Qual Life Outcomes. 2006;4:21

30. Semnani S, Abdolahi N, Roshandel G, Besharat S, Keshtkar A, Moradi A, et al. Irritable bowel syndrome in students of Golestan University of Medical Sciences. Govaresh. 2012;11(4):249-54.

31. Kanazawa M, Drossman DA, Shinozaki M, Sagami Y, Endo Y, Palsson OS, et al. Translation and validation of a Japanese version of the irritable bowel syndrome-quality of life measure (IBS-QOL-J). Biopsychosoc Med. 2007;1:6.

32. Keogh E, Bond FW, Flaxman PE. Improving academic performance and mental health through a stress management intervention: outcomes and mediators of change. Behav Res Ther. 2006;44(3):339-57.

33. Jamali R, Jamali A, Poorrahnama M, Omidi A, Jamali B, Moslemi $\mathrm{N}$, et al. Evaluation of health related quality of life in irritable bowel syndrome patients. Health Qual Life Outcomes. 2012;10:12.

34. Muscatello MR, Bruno A, Pandolfo G, Mico U, Stilo S, Scaffidi M, et al. Depression, anxiety and anger in subtypes of irritable bowel syndrome patients.J Clin Psychol Med Settings. 2010;17(1):64-70.

35. Lackner JM, Jaccard J, Krasner SS, Katz LA, Gudleski GD, Blanchard EB. How does cognitive behavior therapy for irritable bowel syndrome work? A mediational analysis of a randomized clinical trial. Gastroenterology. 2007;133(2):433-44.

36. Creed F, Ratcliffe J, Fernandez L, Tomenson B, Palmer S, Rigby C, et al. Health-related quality of life and health care costs in severe, refractory irritable bowel syndrome. Ann Intern Med. 2001;134(9 Pt 2):860-8.

37. Lee OY, Fitzgerald LZ, Naliboff B, Schmulson M, Liu C, Fullerton S, et al. Impact of advertisement and clinic populations in symptoms and perception of irritable bowel syndrome. Aliment Pharmacol Ther. 1999;13(12):1631-8.

38. Hasler WL, Chung O, Yamada T. Irritable Bowel Syndrome. In: Gastroenterology.Philadelphia: Lippincott Williams \& Wilkins; 2003.

39. Solati Dehkordi SK. The comparative effect of cognetive - behavioral treatment, education of life style, relaxation and medication on quality of life: prevalence, psychological symptoms and severity in patients with Irritable bowel syndrome.Isfahan: The University of Isfahan; 2008.

40. American College of Gastroenterology Task Force on Irritable Bowel S, Brandt LJ, Chey WD, Foxx-Orenstein AE, Schiller LR, Schoenfeld PS, et al. An evidence-based position statement on the management of irritable bowel syndrome. Am J Gastroenterol. 2009;104 Suppl 1:S1-35.

41. Kovacs Z, Kovacs F. Depressive and anxiety symptoms, dysfunctional attitudes and social aspects in irritable bowel syndrome and inflammatory bowel disease. Int J Psychiatry Med. 2007;37(3):245-55. 